\title{
The role of self-determined motivation and goals for study abroad in the adaptation of international students
}

\author{
Valery Chirkov $^{\mathrm{a}, *}$, Maarten Vansteenkiste ${ }^{\mathrm{b}}$, \\ Ran Tao ${ }^{\mathrm{a}}$, Martin Lynch \\ ${ }^{a}$ Department of Psychology, University of Saskatchewan, Saskatoon SK, Canada \\ ${ }^{\mathrm{b}}$ Department of Psychology, University of Leuven, Leuven, Belgium \\ ${ }^{\mathrm{c}}$ Department of Psychology, University of South Florida/Sarasota-Manatee, Sarasota FL, USA
}

Received in revised form 6 March 2004; accepted 9 March 2006

\begin{abstract}
Two studies with Chinese international students in Belgium and Canada investigated the role of two motivational factors in students' decision to study abroad: the level of self-determined motivation and the content of their goals. A newly developed questionnaire, the Self-regulation Questionnaire-Study Abroad was used to test the hypothesis that self-determined motivation to study abroad would be more beneficial for students' adaptation outcomes than non-self-determined motivation. This hypothesis was generally supported. Using the Goals for Study Abroad Scale, the two-factor structure of students' goals was discovered. It consisted of a 'Preservation factor', which reflects the goals of avoiding disadvantageous conditions in the home country, and a 'Selfdevelopment factor', which reflects the goal of pursuing good education and better career opportunities abroad. The preservation goals were negatively related with cultural adaptation indicators. The level of self-determination and the goals to study abroad had an independent effect on cultural adaptation of the students. The potential applications of these two motivational parameters to study migration motivation were discussed.
\end{abstract}

(C) 2006 Elsevier Ltd. All rights reserved.

\footnotetext{
*Corresponding author. Tel.: + 13069666529 ; fax: + 13069666630.

E-mail addresses: v.chirkov@usask.ca (V. Chirkov), Maarten.Vansteenkiste@psy.kuleuven.be (M. Vansteenkiste), ran.tao@usask.ca (R. Tao), lynch@banshee.sar.usf.edu (M. Lynch).
} 


\section{Introduction}

International students constitute a significant portion of student bodies in many universities around the world, and their academic success, health, and psychological wellbeing (PWB) are important issues for the students themselves, for university administration and for research communities (Buddington, 2002; Furnham \& Bochner, 1986; Glennon \& MacLachlan, 2000; Nipoda, 2002; Schwartz, 1973; Selltiz \& Cook, 1962; Selltiz, Crist, Havel, \& Cook, 1963; Toyokawa \& Toyokawa, 2002; Walker, 1999). In this article, we report the results of two studies in which we investigated the role of the motivation to study abroad in predicting Chinese international students' adaptation to a new environment in Belgium and Canada. After a brief overview of the state of migration motivation research, we introduce the self-determination theory (SDT) of human motivation (Deci \& Ryan, 2002; Ryan \& Deci, 2000, 2001), which served as a theoretical basis for the present studies, propose how it may be applied to the study of migration processes, and present our hypotheses before proceeding to the empirical part of the project.

\subsection{Motivation to move abroad: state of the art}

Because moving to a different country is an important life-changing decision, it seems obvious that various reasons and motives, including economic, political, and religious ones (Hall, 2004), play a role therein. Accordingly, many models of migration and cultural adaptation have included motivational factors as important determinants of both the migration and adaptation processes (Berry, 1997; Kim, 2001; Rumbaut, 1991; Scott \& Scott, 1989; Ward, Bocher, \& Furnham, 2001). Economists, sociologists, and psychologists usually approach individuals' motivation for moving abroad differently, yet in line with the main focus and paradigms of their disciplines. For instance, economists approach the analysis of international migration from the point of view of the international division of labor and different demands for labor in different countries (Massey, 1999). Sociologists identify structural, political and social factors that motivate migrants to move to another country (Richmond, 1993). The socioeconomic approach to understanding international migration has given rise to the most well-known conceptualization of migration motivational factors: the push and pull model of international migration (Bierbrauer \& Pedersen, 1996; Martin, 1993; Richmond, 1993). According to Martin (1993) "migration occurs between demand-pull factors that draw migrants into industrial countries, supply push factors that push them out of their own countries, and a network of friends and relatives already in industrial societies who serve as anchor communities for newcomers" (p. 4). Within the sociological interpretation of this model, refugees, for example, are viewed as migrants 'pushed' by perceived threats to their life, liberties, or faith, whereas voluntary migrants are portrayed as 'pulled' by perceived hopes for a better future and promising economic opportunities (Rumbaut, 1991). Notably, in addition to the 'push' and 'pull' factors, the network of friends and relatives in host counties has been identified as an important socio-psychological factor in the motivation to migrate. This and other socio-psychological factors of migration have been accepted by various scholars, including economists, sociologists and psychologists (Booth, Crouter, \& Landale, 1997).

Psychologists typically work to understand people's motives and intentions to move to another country on an individual level, and they investigate this problem from different 
theoretical and methodological perspectives (Winchie \& Carment, 1988). For example, the psychoanalytic approach to studying immigrants' experience (Elovitz \& Kahn, 1997) and their motivation (Marlin, 1997) might lead researchers to utilize projective methods in their studies (Fass, 2003). Another approach aimed to apply McClelland's three-motive model of human motivation (based on the motives for achievement, power, and affiliation) to the situation of international migration (Boneva \& Frieze, 2001; Frieze et al., 2004). These studies demonstrated using psychological scales and survey methodology that people who are willing to emigrate possess higher levels of achievement and power motivation and lower levels of affiliation motivation in comparison to those who decide to stay in their home country. Similar studies have been conducted in the area of economic psychology (Winter-Ebmer, 1994) and have demonstrated that immigrants with a high level of 'need for success' economically outperform people without this motivation or people who emigrated for political reasons.

In addition to these dispositional motives, people's values have also been considered to be an important motivational factor in making the decision to move abroad. Boneva, Frieze, and their colleagues (Boneva \& Frieze, 2001; Boneva et al., 1998; Frieze et al., 2004), for example, considered values, such as work or family orientation, together with dispositional motives, to be key determinants of the decision to move abroad. In particular, they found that emigrants score higher on work orientation and lower on family orientation in comparison to those who stay.

Tartakovsky and Schwartz (2001) conducted a study of young Jews planning to move from Russia to Israel and found three emigration motives, specifically, preservation, which refers to physical, social, and psychological security, self-development, which refers to personal growth in abilities, knowledge and skill development, and materialism, which reflects the desire for financial success and wealth. This classification was rooted in Schwartz's (1992) value model. These researchers showed that the three emigration motives have different psychological content and relate differently to emigrants' values. Specifically, they found that preservation motivation correlated negatively with the Openness to Change values (preference for intellectual and emotional challenge, novelty, risk and unpredictability) and positively with the Conservation values (emphasis on maintaining the status quo and avoiding risk); whereas self-development motivation had the exact opposite pattern of associations with the same values. Materialistic motivation (which was the strongest motivation in the studied sample) was related positively to SelfEnhancement (emphasis on self-interest) and negatively to Self-Transcendence values (stress on the interests and goals of others even at cost to self), demonstrating the substantial role of the motivation in promoting self-interest through achievement and control over resources. They also related these three migration motives to emigrants' wellbeing (WB), thereby showing that self-development (but not preservation neither materialism) was positively associated with various indicators of emigrants' WB.

Despite the importance of psychological studies of migration motivation and the existence of several interesting approaches, research on the motivation of international students to study abroad and on the motivation of other groups of migrants (immigrants, refugees, sojourners, etc.), is not a well-developed research area, either conceptually or methodologically. Although the majority of the studies mentioned represents the application of general theories of motivation - the psychoanalytic theory, MacClelland's theory of motivation, Schwartz' values theory - to the migration domain, many contemporary theories of motivation are waiting to be applied to migration research 
and supply researchers with new ideas. Both cognitive-based motivation theories that focus on the concept of goals (Eccles \& Wigfield, 2002; Gollwitzer \& Bargh, 1996; Locke \& Latham, 2002; Pervin, 1989) and more experiential theories that are build around the concept of human needs (Deci \& Ryan, 2000; Doyal \& Gough, 1991; Ramsay, 1992) could be relevant to the study of migration motivation. The above-mentioned studies of Tartakovsky and Schwartz (2001) and the research on goal orientations of migrants by Gong $(2003$, 2006) represent some of the recent examples of the application of the current theories of human motivation to study migration motivation. Despite these promising attempts, further efforts are required to narrow the gap between the rich theoretical traditions of motivational psychology and the more limited theoretical base of current research on migration motivation. Furnham \& Bochner (1986) criticized the existing migration motivation literature for its dearth of empirical studies on this topic, and they found fault with the existing studies for their oversimplified and atheoretical nature. Although these comments were made about 20 years ago, these authors' warnings for acculturation and immigration researchers are still valid today. More recently, the lack of systematic studies on migration motivation has also been mentioned by Rumbaut (1991) and Schmitz (2001). These critical evaluations of the state of migration motivation research encouraged us to look for new theoretical models and constructs that could be applied to the studies of migration motivation, and we find them within the tenets of the SDT of human motivation. Because previous research on migration motivation has studied the motivation of emigrants, whereas the motivation of international students remained relatively understudied, we focused on the latter in the current manuscript. Thus, we decided to apply constructs from SDT to study international students' motivation to study abroad.

\subsection{SDT of human motivation and its application to migration motivation}

The approach of the present article is a psychological one and is guided by SDT, a theory of personality, human motivation and optimal functioning (Ryan \& Deci, 2001, 2002). SDT is an empirically based organismic theory of human motivation which continues the traditions of humanistic and existential theories of human functioning (Ryan \& Deci, 2004). According to SDT, there are two aspects of motivation that need to be studied: the level of self-determination of people's behavior and the content of the goals they strive for (Deci \& Ryan, 2000; Sheldon, Ryan, Deci, \& Kasser, 2004).

As claimed by SDT, any behavior can differ in its degree of experienced selfdetermination, that is, people can engage in an activity because they put their selves behind it and have a feeling of ownership of their behavior or they can feel pressured to partake in the activity (Deci \& Ryan, 1985). Research guided by SDT has demonstrated that a more self-determined motivation of one's behavior brings many advantages, in terms of the quality of performance as well as in terms of the WB of the performer (Deci \& Ryan, 2002).

Within SDT, the level of self-determination is assessed by considering the degree to which a person's behavior is experienced as autonomous and volitional versus controlled and coerced. Two different types of autonomous motivation are distinguished, that is intrinsic motivation and internalized extrinsic motivation. When intrinsically motivated, people engage in the activity for its own sake and because of the interest and enjoyment that it generates. For instance, if students move to a foreign university because they find 
this move to be challenging and exciting, they are said to be intrinsically motivated. Intrinsic motivation is the prototype of autonomous motivation, because people are willingly engaging in the activity only for its own sake, because the activity meets their interests and not because of the expectation of rewards. People can also be autonomously motivated if the behavior they are involved in is relevant to their values and personally important to them. In this case, the behavior is said to have an identified regulation. Identified regulation represents a form of extrinsic motivation, because individuals are engaging in the activity to attain outcomes that are external to the activity itself (i.e., achieving their self-selected goals via the activity), but they have internalized these initially external outcomes and made them personally relevant goals, so that they are experienced as autonomous. With regard to moving abroad identified regulation takes place when students decided to study in a foreign country because this move is relevant to their personally important career and life goals.

People sometimes fail to successfully internalize the regulation of their behavior, as in the case of external and introjected regulation. In the case of external regulation, people are performing the activity to avoid punishment or to obtain external rewards. Students who have decided to study abroad because their parents insisted on it and promised rewards for doing this provide a good example of this form of regulation. When people are engaging in the activity to avoid feeling guilty or to gain social approval by meeting the expectations of others, they are said to have introjected regulation of the activity, that is, they have partially internalized the activity. The regulation resides now within the person, but the activity engagement is still experienced as coerced and alien to one's self. If students have not experienced direct pressure from other people regarding their decision to study abroad, but feel that they 'should' or 'ought' to do this because this is what others expect of them , then they demonstrate an introjected regulation of their behavior.

SDT maintains that these four types of behavioral regulation, that is, intrinsic, identified, introjected, and external can be situated along a self-determination continuum, with external regulation representing a complete lack of self-determined motivation and intrinsic motivation representing the fullest type of self-determined motivation. Then, in empirical research, in which all four regulatory styles are assessed, a composite score of self-determined motivation, called the Relative Autonomy Index (RAI), is created by weighting these four scales depending on their placement on the self-determination continuum. Specifically, intrinsic, identified, introjected and external regulations are given a weight of $+2,+1,-1$ and -2 , respectively. Thus, one of the aims of the present studies was to apply these four regulatory styles to study the motivation of international students and investigate the capability of these styles to predict students' social adaptation.

Although these levels of self-determination in migration motivation have never been studied empirically, the potential to enrich the study of various groups of migrants by applying this theoretical framework seems apparent. With respect to the immigration literature, some indications of this dimension can be found in attempts to differentiate 'voluntary' from 'forced' (Ekblad, Kohn, \& Jansson, 1998) and 'proactive' from 'reactive' migration (Richmond, 1993). In a study of the adaptation of Indochinese refugees in the US, Rumbaut (1991) thoroughly investigated the content of the motivation of these migrants and classified their motives along a dimension 'Degree of Perceived Danger and Lack of Control in Decision to Leave'. He discovered that the motives with the highest degree of perceived fear and lack of control had the highest positive correlations with psychological distress and a negative correlation with the willingness to be acculturated in 
American society in comparison to the motives with less fear and more control. Although the author did not separate the fear factor from the lack of control factor (which generally reflects low self-determination) in making a decision to leave, we believe that the latter aspect played a significant role in predicting the negative outcomes of the refugees' adaptation and is worth of studying as an independent factor.

Following these assumptions, we hypothesized that the motivation of international students to study abroad can also differ in its degree of self-determination (Chirkov, Tao, Vansteenkiste, \& Lynch, 2004, Chirkov \& Vansteenkiste, 2005). We expect that a more self-determined motivation to study abroad would positively predict various indicators of the students' academic, social, and cultural adaptation.

Within the framework of SDT, not only does the level of autonomy matter, but so also does the content of the goals that people are pursuing. People differ in their motivation not only with regard to the level of self-determination of their action but also with regard to the specific substance of the goals and intentions that they pursue in their behavior.

SDT researchers have focused on the distinction between intrinsic or extrinsic goals (Kasser \& Ryan, 1993, 1996). Intrinsic goals, such as meaningful relationships, personal growth and societal contribution, correspond to satisfaction of humans' basic psychological needs - in SDT, the needs for autonomy, competence and relatedness - and thus produce healthy outcomes. Extrinsic goals, such as financial success, popularity and fame, and physical attractiveness, on the other hand, do not correspond to humans' natural, need-based tendencies and hence may be detrimental to human growth and functioning (Kasser \& Ryan, 1993, 1996; Vansteenkiste, Lens, \& Deci, in press b). This classification of people's goals and the positive effect of the relative importance of intrinsic over extrinsic goals on people's WB has been supported by several cross-cultural studies (Ryan et al., 1999; Schmuck, Kasser, \& Ryan, 2000; Vansteenkiste, Duriez, Simons, \& Soenens, in press a). There have been debates in the literature about the relations between the level of selfdetermination and the content of life goals in predicting people's WB (Carver \& Baird, 1998; Srivastava, Locke, \& Bartol, 2001). The bottom line of these debates is that it is not the content of peoples' motivation (intrinsic vs. extrinsic goals) but their level of autonomy that actually predict people's WB, meaning that goal content does not have an independent effect on WB controlling for the level of self-determination. SDT researchers (Sheldon et al., 2004) have addressed these debates, thereby showing that goal content and the level of autonomy explained independent variance in participants' WB. To test this independent effect became one of the goals of our study.

It is important to note here that the content of people's motivation can be addressed at different conceptual levels. SDT researchers study the content aspect of people's motivation at the level of life aspirations or central life-guiding principles (Kasser \& Ryan, 1996; Ryan et al., 1999). This life-goals concept is very close in its meaning to a values concept which has been defined as 'desirable, transsituational goals, varying in importance, that serve as guiding principles in people's lives' (Tartakovsky \& Schwartz, 2001, p. 89). The content of goals for a particular activity may reflect to some extent these life aspirations, but usually these goals are more situation-specific and depend on various contextual attributes and the characteristics of the activity and persons involved. (See as an example the research of Tartakovsky \& Schwartz (2001), who identified the specific motives for emigration based on the nearly universal model of human values (Schwartz, 1992)).

Thus, we believe that the goals of international students, which we addressed in our studies, are not their life-guiding principals but more specific situational objectives that are 
shaped by their situation in the home country, relationships with families, future career goals and other conditions. Therefore, we decided to explore the content of the international students' goals and the relations these goals have to students' adjustment outcomes.

The content of motivation is well presented in the acculturation and migration psychology literature. We have already mentioned the push and pull theory of migration motivation (see Richmond, 1993), family or work orientations (Frieze et al., 2004), and preservation, materialistic and self-development motives (Tartakovsky \& Schwartz, 2001). An interesting classification of refugees' motives was suggested by Rumbaut (1991). He distinguished six groups of motives arranged along two dimensions: the Degree of Perceived Danger and Lack of Control in Decision to Leave, and the Type of Motives, where Type A was political motives and Type B was economic and personal motives. As a result of this arrangement, he identified the Type A motives as (1) Force or Fear (the motive with the highest degree of perceived danger and lack of control), (2) Past associations with American Military or CIA and (3) Ideological (with the least degree of perceived danger and lack of control). For Type B motives, he identified (1) Harsh conditions/Poverty, (2) Property loss and (3) "Pull" motives (seeking a better future; better education, and so forth). We suggest that this classification reflects to a certain degree the more theoretically based distinction, proposed in our study, between the self-determined motivation dimension represented in Rumbaut's scheme by the Degree of Perceived Danger and Lack of Control parameter, and the 'content' dimension represented in that model by Type A and Type B motives.

The relations of these various motives and goals with the level of self-determination and with the PWB of migrants, however, has not, to date, been adequately addressed by researchers. Relatively few researchers have directly addressed the problem of the relations between migration motivation and various indicators of social adaptation and acculturation of migrants. Indeed, these issues have never been studied with regard to international students, who are the focus of the present project.

\section{Present research}

The goal of our study was to test the following hypotheses. First, we expected that international students' motivation to study abroad could be described by two parameters, that is, by the level of their self-determined motivation to study abroad and by the type of goals they set for themselves (i.e., goal content) when moving to a foreign country. This hypothesis is strongly justified by the SDT research and by several migration motivation studies presented above. Second, we anticipated that these two components of motivation would independently predict various indicators of students' cultural adaptation and functioning. Specifically, we hypothesized that self-determined motivation with regard to studying abroad would positively predict students' autonomy in academic motivation, social adaptation and PWB. This assumption is based on the numerous results from the studies guided by SDT which have demonstrated the positive effects of self-determined motivation on various aspects of human functioning. The supposition about the independent role of the level of self-determination and goal content on important outcome variables is based on the recent discovery of this effect by Sheldon and colleagues (Sheldon et al., 2004). We do not have a specific hypothesis regarding the content of the students' goals to study abroad and thus leave this aspect of their motivation open for exploration. 
Our project consisted of two studies. In study 1, we investigated two subsamples of Chinese students: one consisted of candidates wishing to study in Belgium, who were surveyed in the People's Republic of China; the second was comprised of Chinese students who had already started their higher-level education in Belgium. In this study we developed the Self-Regulation Questionnaire-Study Abroad (SRQ-SA), applied it to the above-mentioned samples and used it to predict the students' adjustment outcomes. In study 2, we surveyed Chinese university students in a midsize Canadian University in a Prairie province. In this study, we developed a questionnaire to measure the goals to study abroad and investigated the ability of this measure and the SRQ - SA to predict students' acculturation outcomes. In this study we also created a questionnaire for acculturation motivation and used it as one of the outcome measures.

\section{Study 1}

\subsection{Method}

\subsubsection{Participants and procedure}

Sixty-six male (54\%) and 53 female (43\%) Chinese students participated in the study. Three participants did not provide their gender (total $N=122$ ). The sample consisted of two subsamples, that is, 42 participants ( 24 men, 18 women, average age was 24.5 years) were involved in an application procedure to move to Belgium (we called this subsample 'Applicants') and 80 participants (42 male, 35 female, 3 did not report their gender, with average age 23.3 years) who had already moved to Belgium to study (we labeled this subsample 'Students'). The applicants completed the questionnaires during their application interview (May 2003) which was conducted by a Belgian organization specializing in helping Chinese international students. The students had lived in Belgium for an average of 8 months and were involved in a 1-year preparatory program to learn Dutch to be able to progress to college or university studies. They were surveyed in April 2003. The Chinese participants in both subsamples came from various regions of the People's Republic of China.

\subsubsection{Measures}

All questionnaires were translated from English into Chinese by two native English speakers fluent in Chinese. This translation was in turn independently back translated by two native Chinese teachers who had both been teaching English for at least 5 years. When any problem regarding the adequacy of the back translation arose, it was discussed in the presence of one of the authors, and a solution was agreed on.

Self-Regulation Questionnaire_Study Abroad ( $S R Q-S A$ ): Each subsample of participants was asked a question: 'What was a good reason for you to study abroad?' The questionnaire contains four answers to this question, tapping the four types of motivational regulation postulated by SDT. The first type, external regulation, reflected the extent to which students were motivated to study abroad by pressuring external factors: parents'/relatives' demand or life circumstances. After psychometric analysis, 4 items remained in this subscale with Cronbach's $\alpha=.66$. The full scale is presented in the Appendix. The second type, introjected regulation, indicated how strongly the students who were moving abroad were motivated by internal pressures, such as obligations or a desire to meet other people's expectations. This subscale was constituted by two categories of 
items. One category reflected a desire to avoid guilt and shame for not moving abroad (for example: 'I moved to Belgium because I would feel bad about myself if I didn't'), while the second category reflected a willingness to seek social approval and recognition by studying abroad (e.g., 'I moved to Belgium because I'll get respect and recognition from others for doing so'). After the psychometric analysis, eight items, four for each category, were selected and combined together to form an introjected regulation subscale with $\alpha=.81$. The correlation between these two groups of items was $r(121)=.56, p<.001$. The third type of motivational regulation, identified regulation, represented motivation based on the students' personal commitment to study abroad and the importance of this move to them personally. Four items with Cronbach's $\alpha .81$ were retained in this subscale. The fourth and final type of motivation regulation, intrinsic motivation, represented a type of motivation that is based on perceiving the opportunity to study abroad as an interesting, exciting, inherently satisfying, and challenging experience. Five items with $\alpha .77$ comprised this subscale.

The four subscales formed a simplex-ordered pattern (see Table 1) with subscales closer to each other on the self-determination continuum (e.g., external and introjected regulation) being more strongly correlated with each other than subscales that are conceptually more different (e.g., external and intrinsic regulation) (Ryan \& Connell, 1989). This pattern of correlations allowed us to create an overall score of relative autonomy with respect to moving abroad to study, called the RAI, as has been done in many other studies within the SDT -tradition (e.g., Chirkov, Ryan, Kim, \& Kaplan, 2003). This index, if positive, reflects the relative prevalence of self-determined (autonomous) motivation (i.e., intrinsic and identified regulation) over non-self-determined (controlled) motivation (i.e., external and introjected regulation). A negative valence of this index represents the relative dominance of controlled over autonomous motivation. The means and standard deviations of the RAI for the subsamples are presented in Table 2. For the total sample the RAI parameters were the following: Mean $=7.01, \mathrm{SD}=2.57$, Min $=-2.95$ and $\operatorname{Max}=12.00$.

Goals for studying abroad: To assess the goals for studying abroad, we used a modified version of The Reasons for Emigration Scale (Tartakovsky \& Schwartz, 2001). This scale was initially developed to measure the motivation of young Russian Jews planning to emigrate to Israel. We modified the items to fit the sample of Chinese international students. This scale included 11 items that cover 3 reasons for emigration: preservation (5 items, e.g. 'Concern about national conflicts in the home country', Cronbach's $\alpha$ in our sample $=.67$ ), self-development ( 3 items, e.g. 'Searching for something new and unusual in life', Cronbach's $\alpha=.55$ ), and materialism (4 items, e.g. 'Desire to raise one's standard of

Table 1

Intercorrelations among self-regulation subscales in the total sample of chinese applicants and students $(N=122)$

\begin{tabular}{|c|c|c|c|}
\hline$V$ & 1 & 2 & 3 \\
\hline \multicolumn{4}{|l|}{ 1. Intrinsic motivation } \\
\hline 2. Identified regulation & $.74^{* *}$ & & \\
\hline 3. Introjected regulation & -.02 & .01 & \\
\hline 4. External regulation & $-.24^{*}$ & $-.32^{* *}$ & $.62^{* *}$ \\
\hline
\end{tabular}

${ }^{*} p<.05,{ }^{* * *} p<.01$. 
Table 2

Means, standard deviations, and $t$-tests for the indicators of motivation and well-being of Chinese applicants and students

\begin{tabular}{llllll}
\hline $\begin{array}{l}\text { Subsamples of } \\
\text { participants }\end{array}$ & Statistics & $\begin{array}{l}\text { RAI for } \\
\text { studying abroad }\end{array}$ & $\begin{array}{l}\text { RAI for } \\
\text { academic } \\
\text { motivation }\end{array}$ & $\begin{array}{l}\text { Subjective well- } \\
\text { being }\end{array}$ & $\begin{array}{l}\text { Psychological } \\
\text { well-being }\end{array}$ \\
\hline Applicants & Mean & 7.81 & 5.91 & 1.08 & 1.43 \\
$N=42$ & SD & 1.98 & 1.72 & -.65 & 1.22 \\
Students & Mean & 6.57 & 4.91 & 2.23 & 2.78 \\
$N=80$ & SD & 2.75 & 2.35 & $t(115)=4.22^{* *}$ & $t(114)=5.45^{* *}$ \\
& $t$-test & $t(117)=2.57^{* *}$ & $t(119)=2.43^{*}$ & $d=.79$ & $d .03$ \\
\end{tabular}

$\mathrm{RAI}=$ relative autonomy index.

${ }^{*} p<.05, \stackrel{* *}{p} p<.01$.

living', Cronbach's $\alpha=59$ ). Because of the very low reliabilities of the subscales, we did not include the results for this questionnaire in the analysis. One of the reasons why this scale turned out to be unreliable is because it was initially created for a group of migrants that is different from the Chinese international students. Despite our modification, the items did not reflect the motivation of international students coherently. We conclude from this fact that it may be necessary to develop a different questionnaire to measure specifically the goals of international students to study abroad.

The outcome measures: Because we were studying migration motivation among students, we considered it important to include an academically relevant outcome measure. We thus measured the level of their academic motivation, which has been shown in previous research to be positively related to students' (both high school and college) academic performance and well-being in North America (Deci, Vallerand, Pelletier, \& Ryan, 1991; Reeve, Deci, \& Ryan, 2004; Ryan \& Connell, 1989), China (d'Ailly, 2003; Vansteenkiste, Zhou, Lens, \& Soenens, 2005), Japan (Hayamizu, 1997; Tanaka \& Yamauchi, 2000), Russia (Chirkov \& Ryan, 2001), Germany (Levesque, Zuehlke, Stanek, \& Ryan, 2004) and Belgium (Vansteenkiste, Simons, Lens, Sheldon, \& Deci, 2004). We measured the level of academic motivation by the $S R Q-A$ (Ryan \& Connell) which consists of 13 items designed to measure the level of autonomy in students' academic motivation. The participants were asked about their reasons to do academic work at a college or university and were provided with responses that correspond to the same four types of motivational regulation that were used to measure motivation to study abroad: external, introjected and identified regulation, and intrinsic motivation. All subscales had acceptable internal reliability with Cronbach's $\alpha$ 's higher than .70. The RAI for academic motivation was calculated and interpreted in the same way as for motivation to study abroad: the higher the score, the more self-determined regulation prevails over non-self-determined regulation. Means and standard deviations of the RAI for the subsamples are presented in Table 2. For the total sample the RAI parameters were the following: Mean $=5.26, \mathrm{SD}=2.20$, $\mathrm{Min}=-.60$ and $\operatorname{Max}=10.25$.

Subjective well-being ( $S W B$ ): SWB was assessed by the Positive Affect Negative Affect Schedule (PANAS; Watson, Tellegen, \& Bartol, 1988) and the Satisfaction with Life Scale (SWLS; Diener, Emmons, Larsen, \& Griffin, 1985). The PANAS consisted of 20 mood 
adjectives, 10 positive (e.g., 'excited', 'pleased') and 10 negative (e.g., 'ashamed', 'distressed'). Participants were asked to rate how much they had experienced each mood 'in the past month or so' using a 5-point rating scale, with $1-$ Not at all to 5-Extremely. The SWLS consisted of five items which allowed participants to evaluate their lives using a 5-point Likert rating scale ranging from 1-Completely Disagree to 5-Completely Agree. Internal consistency of these two scales for the total sample and for both subsamples was .81 or higher. A composite score of overall SWB was created by standardizing and summing positive affect and life satisfaction $(r(115),=.40 p<.01)$ and subtracting standardized negative affect scores $(r(115)=-.42, p<.01$ [with life satisfaction] and $r$ $(115)=-.25, p<.05$ [with positive affect]).

$P W B$ : We used the seven-item Vitality scale (Ryan \& Frederick, 1997) to assess participants' global feelings of energy, vigor, and aliveness over the past few months. Previous research (Nix, Ryan, Manly, \& Deci, 1999) has found it to represent eudaimonic PWB. Items were rated on a 5-point Likert scale ranging from 1-Completely Disagree to 5-Completely Agree. Cronbach's $\alpha$ 's were .84 in the total sample and .80 and .82 in the two subsamples, respectively. Depressive feelings were measured by the 20 -item Center for Epidemiological Studies-Depression (CES-D) scale (Radloff, 1977). Participants were asked to indicate how often they experienced specific depressive symptoms during the past week. Ratings were made on a scale ranging from 0 to 3 , with 0 -rarely or none of the time (less than one day), 1-a couple of times (1-2 days), 2-sometimes or regularly (3-4 days), and 3 - most or all of the time (5-7 days). For each individual, a total severity of depressive symptoms score was calculated by summing the responses which resulted in a possible range of depression scores from 0 (low depressive symptoms) to 60 (high depressive symptoms). Cronbach's $\alpha$ was .92 in the total sample, and .80 and .93 in the subsamples of applicants and students, respectively. The overall index of PWB was also calculated using the standardized scores of these two scales; $r$ (for the whole sample, 115 ) $=-.59, p<.001$ Depression was entered with the negative sign.

\subsubsection{Results of Study 1}

3.1.3.1. Preliminary analyses. Two separate independent $t$-tests were executed to test for gender-effects and to examine whether both subsamples differed on any of the outcome variables. Male and female participants did not differ on any of the outcomes; hence, gender was discarded as a predictor from further analyses. We then compared the means of all measured indicators for the two subsamples. As can be seen in Table 2, the applicants had higher levels of both kinds of motivation and WB in comparison to students. Although the effect sizes for motivation were medium, the differences in WB were large in terms of the effect sizes. This is understandable: the applicants were full of anticipation of the future move to Europe, they had a more self-determined motivation to study abroad, and were happy and satisfied with this opportunity. The students, in contrast, were possibly experiencing culture shock and perhaps other negative consequences of the move to Belgium, which likely negatively affected their levels of life satisfaction, mood, and vitality. Although this explanation is speculative, it stresses the importance of studying the changes in psychological functioning of international students when they move from their home country to a foreign one.

3.1.3.2. Primary analyses. Next, we correlated the RAI for studying abroad with the RAI for academic motivation and the indicators of WB (see Table 3). All correlations were 
Table 3

Correlations of the relative autonomy index (RAI) for study abroad with academic motivation and indicators of well-being of Chinese applicants and students

\begin{tabular}{llll}
\hline Subsamples of participants & $\begin{array}{l}\text { RAI for academic } \\
\text { motivation }\end{array}$ & $\begin{array}{l}\text { Subjective } \\
\text { well-being }\end{array}$ & $\begin{array}{l}\text { Psychological } \\
\text { well-being }\end{array}$ \\
\hline Applicants $N=42$ & $\mathbf{. 3 5}^{*}$ & $\mathbf{. 2 8}^{+}$ & .24 \\
Students $N=80$ & $\mathbf{. 5 5}^{* *}$ & $\mathbf{. 4 3}^{* *}$ & $\mathbf{. 1}^{* *}$ \\
Combined sample $N=122$ & $\mathbf{. 5 3}^{* *}$ & $\mathbf{. 4 4}^{* *}$ & $\mathbf{. 4 3}^{\text {*** }}$ \\
\hline
\end{tabular}

The corresponding correlations in two subsamples do not differ from each other.

${ }^{+} p<.10,{ }^{*} p<.05,{ }^{* *} p<.01$.

positive and in the predicted direction: the more self-determined was the participants' motivation to study abroad the more self-determined they were in their academic activity, and the more satisfied, happy and energetic they felt themselves. As can be seen in Table 3, the correlation coefficients for applicants did not differ significantly from the corresponding coefficients for students. Regression analysis supported the conclusion that the predictive power of the RAI for studying abroad across the two subsamples did not differ.

3.1.3.3. Brief discussion. Study 1 provides initial support for our predictions. We successfully developed and utilized the SRQ - SA, which revealed that Chinese applicants and students varied with regard to the level of autonomy in their decision to study abroad. We discovered also that applicants, who were at the preliminary stage of their international studies, had higher levels of motivation and WB in comparison to students tested in Belgium. Most importantly, despite these differences, results showed that the more selfdetermined was their decision to study abroad, the more self-determined was the academic motivation and the better was the WB of these Chinese applicants and students.

\section{Study 2}

Study 2 was planned with several goals in mind. First, we wanted to replicate and extend the results of Study 1. Specifically, we wanted to test the validity of the developed SRQ SA on another sample of international students residing in a different country. Second, because of the low reliability of the Motivation for Emigration Scale in Study 1, we could not test our hypotheses regarding the role of the content of students' motivation in their adaptation. In order to do this, our second goal was to develop a new questionnaire to measure this aspect of motivation and test its power to predict various indicators of students' adjustment. Third, we wanted to compare this motivational parameter with the level of self-determined motivation to study abroad in its relation with students' adaptation outcomes. Further, we decided to broaden the indicators of students' adaptation and included several scales that measure socio-cultural and linguistic adaptation of international students. In addition to these conventional indicators of socio-cultural adaptation of international students, we decided to explore the construct of 'acculturation motivation' which was suggested by some researchers (Kim, 2001; Selltiz et al., 1963) and was frequently mentioned in our interviewers with International Student Office staff and international students themselves. International students vary strongly 
with regard to their willingness to be acculturated into a host culture. Thus, the development of the scale to measure this construct and use it as an outcome variable became one of the additional goals of Study 2 .

\subsection{Method}

\subsubsection{Participants and procedure}

Participants for this study were 98 undergraduate and graduate international Chinese students from a midsized Prairie Canadian University. There were 47 men and 51 women, with an average length of stay in Canada of 24.7 months. Ages ranged from 19 to 45 years with a mean of 25.2 years. Participants were recruited through the Chinese International Students Association, and they participated voluntarily without any rewards. They were invited into small groups of 5-8 students where they completed the questionnaires under the supervision of a trained research assistant.

\subsubsection{Measures}

All questionnaires were presented in English.

$S R Q-S A$ : To assess the level of self-determination to study abroad, we used the same questionnaire as in Study 1. Cronbach's $\alpha$ for the external regulation subscale was .79, for introjected regulation .86 , for identified regulation.79, and for intrinsic motivation .72 . The RAI had a mean of 4.62 and standard deviation of 2.61, with scores ranging from -4.06 to 10.82 .

The Goals for study abroad scale: Out of 15 items collected from other questionnaires, through interviews with international students and from the literature pertinent to the goals why students may decide to study abroad, 9 items were selected based on psychometric properties and exploratory factor analyses. We used a direct oblimin oblique technique and extracted 2 factors that explained $56 \%$ of these items' variance. These items, factor loadings, communalities and Cronbach's $\alpha$ 's are presented in Table 4. Based on the content of items and following the categorization suggested by Tartakovsky and Schwartz (2001), Factor 1 (5 items Cronbach's $\alpha=.80$ ) was labelled 'Preservation Factor' which included the goals for studying abroad based on avoiding dangerous and insecure conditions in their home country, and Factor 2 (4 items, Cronbach's $\alpha=.66$ ) was named 'Self-Development Factor' which comprised education and career goals for studying abroad.

Motivation for acculturation scale: We also created the 'Motivation for Acculturation Scale' which was intended to measure the willingness of international students to learn about Canadian culture, to have Canadian friends and finally be acculturated into Canadian society and culture (e.g. 'I am interested in learning more about Canada'; 'I try to avoid interactions with Canadians unless it is absolutely necessary' [reverse coded]). ${ }^{1}$ This 15-item measure had Cronbach's $\alpha=.81$, with mean $=3.78$, and standard deviation $=.48$ on a 5 -point rating scale. In an exploratory mode, we discovered that acculturation motivation did not correlate with the time spent in Canada and had no

\footnotetext{
${ }^{1}$ It is important to differentiate our construct of acculturation motivation from the four acculturation orientations (assimilation, separation, integration and marginalization) which have been intensively utilized in acculturation research (see (Rudmin, 2003). The four-orientation model applies usually to immigrants who settled in the host country permanently. International students are sojourners, who settled in their host country temporarily, and, because of this, these four orientations do not apply to them. There is empirical evidence of the importance of acculturation motivation for foreign students' adjustment (Coelho, 1958; Kim, 2001; Selltiz \& Cook, 1962; Selltiz et al., 1963).
} 
Table 4

Summary of items, factor loadings and communalities for direct oblimin oblique two-factor solution for the goals for study abroad questionnaire

Factor loadings

\begin{tabular}{lll} 
Items & & \\
\hline 1 & 2 & Communality
\end{tabular}

Communality

12. I came to study abroad because I wanted to avoid the unacceptable political and social conditions in my home country.

10. I came to study abroad because I wanted to avoid ethnic and social conflicts in my home country.

11. I came to study abroad because I wanted to have more freedom and be independent.

15. I came to study abroad because I am planning to immigrate in the future.

3. I came to study abroad because I was concerned about security and crime in my home country.

13. I came to study abroad because a foreign university degree will open good employment opportunities for me.

5. I came to study abroad because I wanted to master a foreign language.

9. I came to study abroad because I wanted to get a good education.

2. I came to study abroad because I wanted to expand my career and life opportunities.

\begin{tabular}{|lll|}
$\mathbf{. 8 9}$ & .10 & .80 \\
\hline .86 & .03 & .77 \\
.70 & .28 & .51 \\
.65 & .46 & .53 \\
.64 & .12 & .42 \\
\hline .34 & .76 & .61 \\
\hline .15 & .72 & .52 \\
.11 & .71 & .51 \\
.06 & .60 & .36 \\
\hline
\end{tabular}

correlations with other outcome variables. The role of acculturation motivation in students' adaptation should be studied further.

The outcome measures: We used the Self-Regulation Questionnaire-Academic (SRQ-A) (as in the study 1) to assess the level of students' self-determined motivation in the academic domain. The reliability for external and introjected regulations was .70, for identified regulation .77 and for intrinsic motivation $=.62$. The RAI was calculated as for the SRQ-A (mean = 3.30; $\mathrm{SD}=2.84$; $\operatorname{Min}=-2.58$ and $\operatorname{Max}=10.33$ ).

Following the conventional distinction of the psychological and socio-cultural adjustment of sojourners, we used a set of WB indicator as the signs of psychological adjustment and two scales as the measures of socio-cultural adjustment (Searle \& Ward, 1990; Ward \& Kennedy, 1993).

WB indicators: We used The Satisfaction with Life Scale (Diener et al., 1985) which had an internal reliability of .71 in this sample, a shortened (6 items) version of the CES-D scale (Radloff, 1977) with Cronbach's $\alpha=.82$, and the physical symptoms questionnaire which consisted of 8 items describing various symptoms of ill-being such as 'nervousness or shakiness inside', 'headaches', 'bad sleep,' etc. The internal reliability coefficient for this scale was .86. Based on the intercorrelations among these indicators an overall index of WB was created by summing their standardized scores, with the depression and physical symptoms scores entered with negative signs. ${ }^{2}$

\footnotetext{
${ }^{2}$ Conventionally, life satisfaction is considered to be a cognitive component of subjective (hedonic) WB (Diener, 1984) and together with the PANAS scale, which represents an affective component of SWB, represents the
} 
Socio-cultural adjustment indicators: In addition to these indicators of WB, we assessed the students' language preference, that is, whether they prefer their native or English language in their day-to-day activities, using a modified (5 items) version of the original scale (Barona \& Miller, 1994). Participants were asked to answer questions about their language preference in different social situations: speaking with friends, reading, writing, etc. by using a 5-point rating scale with 1-'Only Native Language'; 3-Both Equally; and 5-'Only English'. Cronbach's $\alpha$ for this scale was .72. We also included The Social Situation Evaluation List (Furnham \& Bochner, 1986) to assess the level of comfort that participants experience in various social situations like 'Making Canadian friends of your own age', 'Dealing with people of higher status (e.g. professor) than you' and 'Complaining about unsatisfactory services on campus.' This questionnaire and its modifications have been widely used for the assessment of sojourners socio-cultural adjustment (Ward \& Kennedy, 1999). The questionnaire consisted of the description of 15 situations, with a reliability of .82. Finally, we asked the participants to report their academic success by reporting their grades for the last three exams and by rating two statements: 'I am satisfied with my academic achievement in Canada' and 'It is difficult to study here' (reversed scoring on a 5-point rating scale). These two measures of academic success were positively correlated $(r=.24, p<.05)$ which allowed us to combine them (standardized scores) into one index of 'Academic Success'.

\subsection{Results of Study 2}

\subsubsection{Preliminary analyses}

Gender did not interact with any other predictor variables in predicting all outcome variables. Thus, we collapsed across genders and performed susbsequent analyses on the whole sample.

\subsubsection{Primary analyses}

Because time spent in a host country is one of the most powerful predictors of cultural adaptation, in all the following analyses we controlled for this parameter.

For both groups of goals to study abroad, we calculated the means and standard deviations and correlated these means with the four types of motivational regulation and the RAI as measured by SRQ-SA. These results are presented in Table 5. Selfdevelopment goals (mean $=3.83, \mathrm{SD}=.73$ ) were more strongly endorsed than preservation ones $($ mean $=1.93, \mathrm{SD}=83 ; t(97)=-19.9, p<.01, d=4.03$ ) by students. Both types of goals could be pursued under either introjected or identified regulation, meaning that whether trying to avoid unacceptable conditions in their home country or pursuing education and career goals, the Chinese students may be driven either by the expectations of others and the desire not to be humiliated if they fail in this undertaking, or by a personal endorsement of the importance of these reasons. The significant difference between these two groups of reasons came with respect to the extreme ends of this motivation continuum. Specifically, when striving for preservation goals, the students feel

(footnote continued)

construct of SWB. Nevertheless, taken separately from the affective indicators, the Satisfaction with Life Scale has frequently been used as a marker of the cognitive aspects of PWB also (Chirkov \& Ryan, 2001; Chirkov et al., 2003). 
Table 5

Means and standard deviations of preservation and self-development goals for study abroad and their partial correlations with the subscales of the self-regulation questionnaire-studying abroad in Chinese international students in Canada after controlling for length of stay in Canada

\begin{tabular}{lllllll}
\hline $\begin{array}{l}\text { Goals for study } \\
\text { abroad }\end{array}$ & $\begin{array}{l}\text { Mean } \\
\text { (SD) }\end{array}$ & $\begin{array}{l}\text { External } \\
\text { regulation }\end{array}$ & $\begin{array}{l}\text { Introjected } \\
\text { regulation }\end{array}$ & $\begin{array}{l}\text { Identified } \\
\text { regulation }\end{array}$ & $\begin{array}{l}\text { Intrinsic } \\
\text { motivation }\end{array}$ & $\begin{array}{l}\text { RAI } \\
\text { Preservation }\end{array}$ \\
$\begin{array}{lllll}1.94 \\
(.83)\end{array}$ & $\mathbf{. 3 8}^{* *}$ & $\mathbf{. 4 1}^{* *}$ & $\mathbf{. 2 8}^{*}$ & .17 & $-.18^{+}$ \\
Self-development & $\begin{array}{l}3.83 \\
(.73)\end{array}$ & .11 & $\mathbf{. 5 5}^{* *}$ & $\mathbf{. 5 3}$ & $\mathbf{. 3 3}$ & .12 \\
$\begin{array}{l}\text { Significance of the } \\
\text { differences }\end{array}$ & $\begin{array}{l}t(97)=-19.9^{* *} \\
d=4.03\end{array}$ & $p<.01$ & n.s. & n.s & $p<.05$ & n.s. \\
\hline
\end{tabular}

${ }^{+} p<.10, \stackrel{*}{p}<<.05, \stackrel{* *}{p} p<.01$.

much more external pressure than when they try to achieve self-development goals. Correspondingly, when choosing self-development goals to study abroad, the students endorsed greater interest, enjoyment and internal satisfaction as their motivators than they did when choosing self-preservation goals. Overall, the relative autonomy index did not differ for these two groups of goals. These results allowed us to conclude that when choosing the preservation goals for studying abroad the students have the tendency to be externally motivated whereas when pursuing self-development goals they are usually more intrinsically regulated.

Next, we correlated all motivational parameters - specifically, the level of selfdetermined motivation and the goals for study abroad - with the indicators of students' adaptation. These results are presented in Table 6 . As expected, the RAI of the motivation to study abroad correlated positively with the self-determination of academic motivation, with willingness to learn more about the Canadian culture and with the overall index of PWB. In addition, there was a marginal positive correlation with academic success. This means that the more students felt that they stood behind their decision to move to Canada, the more self-determined they were in their academic strivings, with the tendency to be more successful in their studies. They also felt themselves better psychologically and were more interested in learning about Canadian culture and accepting it. We discovered that preservation goals have negative associations with the self-determination of academic motivation, with willingness to learn more about the Canadian culture and with the overall index of PWB. These correlations suggest that when international students are driven to another country by the desire to avoid unfavourable conditions in their home country, they may demonstrate low self-determined academic motivation, experience low PWB and low motivation to be accepted by Canadian society.

We also discovered that the content of motivation, in the present case preservation goals, and the level of self-determination of the decision to study abroad, were two independent sources of migration motivation because they independently accounted for variance in the outcome variables, with the level of autonomy always being the stronger predictor than the content of this motivation. Specifically, the RAI for studying abroad, when entered into the regression equation predicting the autonomy of academic motivation at Step 1, explained $18.4 \%$ of the outcome variable's variance $(p<.01)$. When the preservation goals to study abroad were entered into this equation at Step 2, an 
Table 6

Partial correlations of the relative autonomy and the goals to study abroad with the indicators of the adaptation of Chinese international students controlling for their length of stay in Canada $(N=84)$

\begin{tabular}{|c|c|c|c|c|c|c|}
\hline $\begin{array}{l}\text { Goals for study } \\
\text { abroad }\end{array}$ & $\begin{array}{l}\text { Academic } \\
\text { success }\end{array}$ & $\begin{array}{l}\text { RAI for } \\
\text { academic } \\
\text { motivation }\end{array}$ & $\begin{array}{l}\text { Acculturation } \\
\text { motivation }\end{array}$ & Well-being & $\begin{array}{l}\text { Social } \\
\text { situations }\end{array}$ & $\begin{array}{l}\text { Foreign } \\
\text { language } \\
\text { acquisition }\end{array}$ \\
\hline $\begin{array}{l}\text { RAI for study } \\
\text { abroad }\end{array}$ & $.20^{+}$ & $.44^{* * *}$ & $.34^{* *}$ & $.31^{* *}$ & .04 & .05 \\
\hline Preservation goals & -.05 & $-.22^{*}$ & $-.26^{*}$ & $-.35^{* *}$ & .03 & .11 \\
\hline $\begin{array}{l}\text { Self-development } \\
\text { goals }\end{array}$ & .02 & -.05 & .04 & -.03 & .00 & .00 \\
\hline
\end{tabular}

${ }^{+} p<.10,{ }^{*} p<.05,{ }^{* *} p<.01$.

additional $3.1 \%(p=.06)$ of the outcome variance was explained. When both predictors were in the equation, beta for the RAI to study abroad was $.40, p<.01$ and for the preservation goals was $-.18, p=.06$. The interaction between these two variables was nonsignificant. Similar relations were discovered for the WB index. When the RAI was entered at Step 1, it explained $9 \%$ of the WB variance $(p<.01)$. The preservation goals, when entered at Step 2, explained an additional $5 \%$ of this outcome variable's variance $(p=.02)$. Beta for the RAI was $.27(p<.01)$ and beta for the preservation goals was -.23 , $(p=.02)$. The interaction between these variables again was nonsignificant.

Self-development goals had no relation with the indicators of adaptation and functioning. Moreover, the motivation to study abroad was not related to the two indicators of social adaptation such as The Social Situations Evaluation List scores and the Preference of English Language Scale. Our small-scale study does not provide enough information to conclude why these results may have happened. Further research is needed to explain the absence of these expected associations.

\section{Discussion of Studies 1 and 2 and Conclusion}

The goal of this study was to investigate the psychological motivation of Chinese international students to study abroad in two countries: Belgium and Canada. We approached this problem within the SDT framework of human motivation. According to this theory there are two aspects of motivation: the level of self-determined motivation and the content of goals that people are striving for. We hypothesized that this conceptualization of motivation could be successfully applied to the study of migration motivation in general, and the motivation of international college students to study abroad in particular. We predicted that if international students were self-determined in their decision to study abroad, meaning that they felt themselves standing personally behind this decision and not driven by other people's expectations or external circumstances, then their adaptation to a new cultural environment would be more successful in comparison to situations in which they were driven by non-self-determined reasons. We expected that the content of goals to study abroad, which we conceptualized at the context-specific level, will be multidimensional, but did not have specific predictions. Because these constructs had never been studied before, the additional goal of the study was to develop scales to measure these variables and test their predictive power. 
In general, our hypotheses were supported. We discovered that the level of selfdetermined motivation for studying abroad could be reliably measured by our newly developed questionnaire, that Chinese international students within each of three samples varied with regard to this motivational parameter and, finally, that this aspect of migration motivation predicted the success of cultural adaptation as measured by various indicators.

To assess the content of motivation to study abroad, we developed a questionnaire to measure the goals to study abroad, which consisted of two factors. One, the Preservation factor, reflected the desire to avoid unfavourable conditions in the students' home country; the second - the Self-development factor-reflected a desire to obtain a good education that could support their successful professional career. We discovered that preservation goals have a tendency to be externally motivated and have negative associations with several indicators of adjustment to a new country. The Self-development goals for studying abroad had a tendency to be more intrinsically motivated, but they did not have any correlation with indicators of adaptation.

Although the ideas of voluntary vs. forced (Ekblad et al., 1998) or reactive vs. proactive (Richmond, 1993) migration have been in the immigration literature for a long time, we believe that this is the first time that the construct of self-determination with regard to migration motivation has been operationalized and used to predict cultural adaptation. The implications of this direction of migration studies are fairly straightforward: regardless of the nature of migration, whether by international students or sojourners, refugees or immigrants, the motivation to move abroad should be considered from the point of view both of its content and of its degree of autonomy or self-determination. We suggest that self-determined migrants are, prototypically, those who have thought a lot about their move to another country, considered the advantages and disadvantages of this decision and have made the decision accepting full responsibility for the potential consequences. Such self-determined people are expected to be personally involved in this act, and the opinions of other people have been used only as sources of information and not as the ultimate determinants of this important decision. It is logical to expect, and our results support this expectation, that such people will work harder, will be more proactive and finally will attain better results with regard to their cultural adjustment in comparison to people who experience that they were forced by various external factors - political and economic conditions, the opinions and expectations of other people, etc. - to move to another country. These results contribute also to long lasting debates about the role and nature of autonomy in different socio-cultural contexts (Chirkov, in press; Chirkov et al., 2003; Markus \& Kitayama, 2003; Miller, 2003; Ryan \& Deci, 2003; Vansteenkiste et al., 2005) by providing one more piece of evidence that when autonomy is conceptualized as a natural human propensity and operationalized through the self-regulation questionnaire based on the propositions of SDT, it may in fact reflect a universal tendency of human beings to be masters of their own actions, which when fulfilled is beneficial for their functioning regardless of the social context.

Our findings concerning the two groups of reasons for studying abroad were not surprising. Immigration researchers have talked about the 'push' and 'pull' factors of migration for a long time. Also, a similar classification of emigration motives has already been suggested (Tartakovsky \& Schwartz, 2001). Conceptually our results are similar to those obtained by these researchers. In our study, the preservation factor was also related negatively to various aspects of students' WB, indicating that the desire to avoid negative conditions in the home country is a negative predictor of health, positive mood and life 
satisfaction. There may by several explanations of these relations. One may suggest that the students who try to avoid disadvantageous conditions in their home country already have poor mental health and because of these deficiencies look for a more secure and safe place to study and live (Tartakovsky \& Schwartz, 2001). Another explanation could come from the research on the approach vs. avoidance distinction in people's personal goals (Elliot, 1999; Elliot, Chirkov, Kim, \& Sheldon, 2001). As stated by these researchers, avoidance personal goals are goals that 'are focused on a negative outcome or state, and regulation involves trying to move or stay away from that outcome or state' (Elliot et al., 2001, p.505). According to the empirical data, avoidance goals relate negatively with people's SWB (Elliot \& Sheldon, 1998; Elliot, Sheldon, \& Church, 1997). So it is possible that students with preservation goals have low WB because of the avoidance nature of this type of goal. One difficulty with this explanation is that the above-mentioned negative associations were discovered in individualistic countries (mostly the US), whereas in collectivistic countries, like South Korea and Russia, avoidance goals do not predict negative WB (Elliot et al., 2001). Further research is needed to study the relations between the avoidance nature of the goals for moving abroad and migrants' WB. The lack of association between self-development goals and adjustment outcomes is a puzzling. In research done by Tartakovsky and Schwartz (2001), self-development motivation was positively related to general mental health and negatively to the feeling of loneliness, thus providing evidence either that the emigrants with high mental health and low loneliness are prone to explore the self-development opportunities immigration provides or that self-development motivation is conducive toward bettering some aspects of emigrants' mental health. It was logical to expect similar relations in our sample of international students. As we have already mentioned, further research is needed to explain this lack of association.

The contribution that our studies make to the existing knowledge on migration motivation, in addition to the operationalization of self-determined motivation to study abroad and providing evidence of the positive relation of this type of motivation with adaptation outcomes, includes that the content of migration motivation and the level of its autonomy are two independent factors that make a separate contribution to students' adjustment outcomes and that these should be considered independently when studying migration motivation. Migrants may have different reasons for moving to another country and they also may have different levels of self-determination behind their reasons.

The greatest limitation of our study is its cross-sectional design. Indeed, the larger question of how the motivation to move to another country influences cultural and social adaptation presupposes a longitudinal design. Specifically, the best way to study this question would be to measure the motivation of actual migrants at Time 1 and then assess their acculturation outcomes at Time 2. Only within this type of design may one talk about the predictive validity of various motivational variables. Currently, we are planning to conduct a longitudinal study along those lines. Another methodological aspect of the study that could be improved is adding a qualitative analysis of open-ended interviews of migrants regarding their experience of being either self-determined or controlled in their decision to move to another country. Because of differences in the cultural meanings of language construction that we used in creating our questionnaires, such a qualitative interview may shed additional light on the cultural specificity of experiencing selfdetermination, or control, during migration. 


\section{Acknowledgements}

This research was supported by a SSHRC grant from the President of the University of Saskatchewan to the first author and by the Grant for Scientific Research Flanders (FWOVlaanderen) to the second author.

\section{Appendix. Self-Regulation Questionnaire—Study Abroad (SRQ—SA)}

There might have been different reasons why you were motivated to move to to study and to live here for a certain period. Please indicate to what extent each of the following reasons to move to applied to you. Some statements may seem very similar to each other but despite this please rate all of them. Use the following scale:

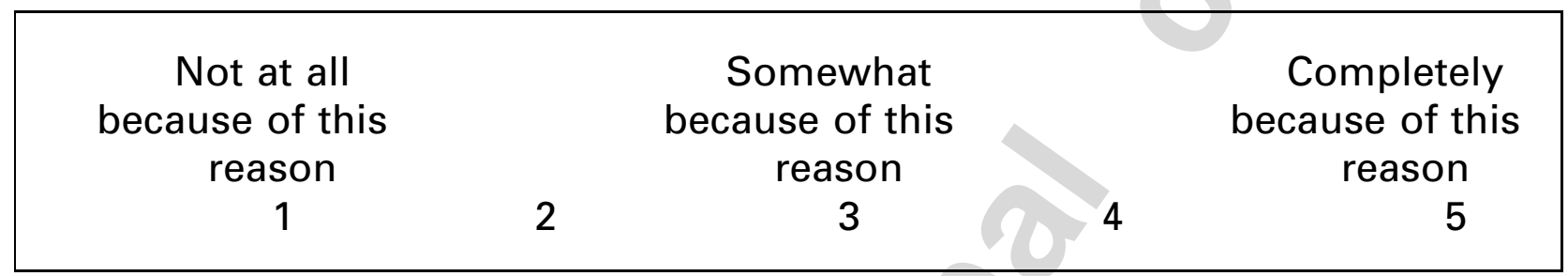

1. I moved to because I thought it would be fun and interesting.

2. I moved to because it was personally important to me.

3. I moved to because other people (relatives and friends) expected me to do this.

4. I moved to so that other people would be proud of me.

5. I moved to because I wanted to avoid the shame and guilt of not doing this.

6. I moved to because I thought I would enjoy it.

7. I moved to because this is what I really want to do with my life.

8. I moved to because others (parents, friends etc.) were pushing me to do this.

9. I moved to because I expected to get respect and recognition from others for doing so.

10. I moved to because it is a prestigious thing to do.

11. I moved to so that other people would approve of me.

12. I moved to because I thought it would be an exciting thing to do.

13. I moved to because others (relatives and friends) forced me to do this.

14. I moved to because it was one of my life goals.

15. I moved to because I would be criticized for not doing so.

16. I moved to because it was of great personal value to me.

17. I moved to because I would have gotten into trouble if I did not.

18. I moved to because it was an opportunity that I highly valued.

19. I moved to because I was highly interested in doing this.

20. I moved to

21. I moved to because that's what I was expected to do. because I felt that I was forced to do so.

External regulation: items $8,13,17,21$

Introjected regulation: items 3, 4, 5, 9, 10, 11, 15, 20

Identified regulation: items 2, 7, 14, 16, 18

Intrinsic motivation: items $1,6,12,19$

Relative Autonomy Index $(\mathrm{RAI})=2$ Intrinsic + Identified - Introjected -2 External 


\section{References}

Barona, A., \& Miller, J. A. (1994). Short acculturation scale for hispanic youth (SASH-Y): A preliminary report. Hispanic Journal of Behavioral Sciences, 16, 155-162.

Berry, J. W. (1997). Immigration, acculturation, and adaptation. Applied Psychology: An International Review, 46(1), 5-68.

Bierbrauer, G., \& Pedersen, P. (1996). Culture and migration. In G. R. Semin, \& K. Fiedler (Eds.), Applied social psychology (pp. 399-422). London: Sage.

Boneva, B. S., \& Frieze, I. H. (2001). Toward a concept of a migrant personality. Journal of Social Issues, 57(3), 477-491.

Boneva, B. S., Frieze, I. H., Ferligoj, A., Jarosova, E., Pauknerova, D., \& Orgocka, A. (1998). Achievement, power, and affiliation motives as clues to (e)migration desires: A four-countries comparison. European Psychologist, 3(4), 247-254.

Booth, A., Crouter, A. C., \& Landale, N. (Eds.). (1997). Immigration and the family: Research and policy on US immigrants. Mahwah, NJ: Lawrence Erlbaum Associates.

Buddington, S. A. (2002). Acculturation, psychological adjustment (stress, depression, self-esteem) and the academic achievement of Jamaican immigrant college students. International Social Work, 45(4), 447.

Carver, C. S., \& Baird, E. (1998). The American dream revisited: Is it what you want or why you want it that matters? Psychological Science, 9, 289-292.

Chirkov, V.I. (in press). Culture, personal autonomy and individualism: Their relationships and implications for personal growth and well-being. In G. Zheng, K. Leung, \& J. Adair (Eds.), Perspectives and progress in contemporary cross-cultural psychology. Beijing, China: China Light Industry Press.

Chirkov, V. I., \& Ryan, R. M. (2001). Parent and teacher autonomy-support in Russian and US adolescents: Common effects on well-being and academic motivation. Journal of Cross-Cultural Psychology, 32(5), $618-635$.

Chirkov, V. I., Ryan, R. M., Kim, Y., \& Kaplan, U. (2003). Differentiating autonomy from individualism and independence: A self-determination theory perspective on internalization of cultural orientations and wellbeing. Journal of Personality and Social Psychology, 84(1), 97-110.

Chirkov, V., Tao, R., Vansteenkiste, M., \& Lynch, M. (2004, August). Motivation to study abroad, acculturation motivation, and adaptation of Chinese students in Canada. Paper presented at the XVII international congress of the international association for cross-cultural psychology, Xi'an, China.

Chirkov, V., \& Vansteenkiste, M. (2005). The Role of Motivation, Reasons to Study Abroad and Acculturation Motivation in the Adaptation of International Students. Paper presented at the 66th CPA annual convention, Montreal, Quebec.

Coelho, G. (1958). Changing images of America: A study of Indian students perceptions. New York: Free Press.

d'Ailly, H. (2003). Children's autonomy and perceived control in learning: A model of motivation and achievement in Taiwan. Journal of Educational Psychology, 95(1), 84-96.

Deci, E. L., \& Ryan, R. M. (1985). Intrinsic motivation and self-determination theory of human behavior. New York: Plenum.

Deci, E. L., \& Ryan, R. M. (2000). The "what" and "why" of goal pursuits: Human needs and the selfdetermination of behavior. Psychological Inquiry, 11(4), 227-268.

Deci, E. L., \& Ryan, R. M. (Eds.). (2002). Handbook of self-determination research. Rochester, NY: The University of Rochester Press.

Deci, E. L., Vallerand, R. J., Pelletier, L. G., \& Ryan, R. M. (1991). Motivation and education: The selfdetermination perspective. The Educational Psychologist, 26, 325-346.

Diener, E. (1984). Subjective well-being. Psychological Bulletin, 93(3), 542-575.

Diener, E., Emmons, R. A., Larsen, R. J., \& Griffin, S. (1985). The satisfaction with life scale. Journal of Personality Assessment, 49, 71-75.

Doyal, L., \& Gough, I. (1991). A theory of human needs. New York: Guilford Press.

Eccles, J. S., \& Wigfield, A. (2002). Motivational beliefs, values, and goals. Annual Review of Psychology, 53(1), $109-132$.

Ekblad, S., Kohn, R., \& Jansson, B. (1998). Psychological and clinical aspects of immigration and mental health. In S. O. Okpaku (Ed.), Clinical methods in transcultural psychiatry (pp. 42-66). Washington, DC: American Psychiatric Association. 
Elliot, A. (1999). Approach and avoidance motivation and achievement goals. Educational Psychologist, 34 , $169-189$.

Elliot, A. J., Chirkov, V. I., Kim, Y., \& Sheldon, K. M. (2001). A cross-cultural analysis of avoidance (relative to approach) personal goals. Psychological Science, 12, 505-510.

Elliot, A., \& Sheldon, K. M. (1998). Avoidance personal goals and personality-illness relationship. Journal of Personality and Social Psychology, 75, 1282-1299.

Elliot, A., Sheldon, K. M., \& Church, M. (1997). Avoidance personal goals and subjective well-being. Personality and Social Psychology Bulletin, 23, 915-927.

Elovitz, P. H., \& Kahn, C. (Eds.). (1997). Immigrant experiences: Personal narrative and psychological analysis. Madison, NJ: Fairleigh Dickinson University Press.

Fass, S. W. (2003). Motives and values of immigrant students: The case of Russian immigrants in Israel; cultural and social variables. Dissertation Abstracts International Section A: Humanities and Social Sciences, 63(12-A).

Frieze, I. H., Boneva, B. S., Sarlija, N., Horvat, J., Ferligoj, A., Kogovsek, T., Miluska, J., Popova, L., Korobanova, J., Sukhareva, N., Erokhina, L., \& Jarosova, E. (2004). Psychological differences in stayers and leavers: Emigration desires in central and eastern European university students. European Psychologist, 9(1), 15-23.

Furnham, A., \& Bochner, S. (1986). Culture shock: Psychological reactions to unfamiliar environments. London: Methuen.

Glennon, S., \& MacLachlan, M. (2000). Stress, coping and acculturation of international medical students in Ireland. In M. MacLachlan, \& M. O'Connell (Eds.), Cultivating pluralism: Psychological, social and cultural perspectives on a changing Ireland (pp. 259-277).

Gollwitzer, P. M., \& Bargh, J. A. (Eds.). (1996). The psychology of action: Linking cognition and motivation to behavior. New York: Guilford Press.

Gong, Y. (2003). Goal orientations and cross-cultural adjustment: An exploratory study. International Journal of Intercultural Relations, 27(3), 297-305.

Gong, Y., \& Fan, J. (2006). Longitudinal examination of the role of goal orientation in cross-cultural adjustment. Journal of Applied Psychology, 90(1), 176-184.

Hall, L. (2004). Dictionary of multicultural psychology: Issues, terms, and concepts. Beverley Hills, CA: Sage.

Hayamizu, T. (1997). Between intrinsic and extrinsic motivation: Examination of reasons for academic study based on the theory of internalization. Japanese Psychological Research, 37, 98-108.

Kasser, T., \& Ryan, R. M. (1993). A dark side of the American dream: Correlates of financial success as a central life aspiration. Journal of Personality and Social Psychology, 65, 410-422.

Kasser, T., \& Ryan, R. M. (1996). Further examining the American dream: Differential correlates of intrinsic and extrinsic goals. Personality and Social Psychology Bulletin, 22, 280-287.

Kim, Y. Y. (2001). Becoming intercultural: An integrated theory of communication and cross-cultural adaptation. Thousand Oaks, CA: Sage.

Levesque, C., Zuehlke, A. N., Stanek, L. R., \& Ryan, R. M. (2004). Autonomy and competence in German and American university students: A comparative study based on self-determination theory. Journal of Educational Psychology, 96(1), 68-84.

Locke, E. A., \& Latham, G. P. (2002). Building a practically useful theory of goal setting and task motivation: A 35-year odyssey. American Psychologist, 57(9).

Markus, H. R., \& Kitayama, S. (2003). Models of agency: Sociocultural diversity in the construction of action. Nebraska Symposium on Motivation, 49, 1-57.

Marlin, O. (1997). Fleeing for the new and yearning for the old. In P. H. Elovitz, \& C. Kahn (Eds.), Immigrant experiences: Personal narrative and psychological analysis. Cranbury, NJ: Associated University Presses.

Martin, P. L. (1993). The immigration issue. In R. King (Ed.), The new geography of European migrations (pp. 1-16). London: Belhaven.

Massey, D. S. (1999). Why does immigration occur? A theoretical synthesis. In C. Hirschman, P. Kasinitz, \& J. DeWind (Eds.), The handbook of international migration: The American experience (pp. 34-52). New York: Russel Sage Foundation.

Miller, J. G. (2003). Culture and agency: Implications for psychological theories of motivation and social development. Nebraska Symposium on Motivation, 49, 59-99.

Nipoda, Y. (2002). Japanese students' experiences of adaptation and acculturation of the United Kingdom. [W. J. Lonner, D. L. Dinnel, S. A. Hayes, \& D. N. Sattler (Eds.), Online readings in psychology and culture (Unit 8, Chapter 5)]. Center for Cross-Cultural Research, Western Washington University, Bellingham, Washington USA. Retrieved, from the World Wide Web: http://www.ac.wwu.edu/ culture/index-cc.htm 
Nix, G. A., Ryan, R. M., Manly, J. B., \& Deci, E. L. (1999). Revitalization through self-regulation: The effects of autonomous and controlled motivation on happiness and vitality. Journal of Experimental Social Psychology, $35,266-284$.

Pervin, L. A. (Ed.). (1989). Goal concepts in personality and social psychology. Hillsdale, NJ: Lawrence Erlbaum Associates.

Radloff, L. (1977). The CED-D scale: A self-report depression scale for research in the general population. Applied Psychological Measurement, 1, 385-401.

Ramsay, M. (1992). Human needs and the market. Aldershot: Avebury.

Reeve, J., Deci, E. L., \& Ryan, R. M. (2004). Self-determination theory: A dialectical framework for understanding socio-cultural influences on student motivation. In S. V. Etten, \& M. Pressley (Eds.), Big theories revisited. Greenwich, CT: Information Age Press.

Richmond, A. (1993). Reactive migration: Sociological perspectives on refugee movements. Journal of Refugee Studies, 6, 7-24.

Rudmin, F. W. (2003). Critical history of the acculturation psychology of assimilation, separation, integration, and marginalization. Review of General Psychology, 7(1), 3-37.

Rumbaut, R. G. (1991). The agony of exile: A study of the migration and adaptation of Indochinese refugee adults and children. In L. Frederick, J. Ahearn, \& J. L. Athey (Eds.), Refugee children: Theory, research, and services (pp. 53-91). Baltimore: Johns Hopkins University Press.

Ryan, R. M., Chirkov, V. I., Little, T. D., Sheldon, K. M., Timoshina, E., \& Deci, E. L. (1999). The American dream in Russia: Extrinsic aspirations and well-being in two cultures. Personality and Social Psychology Bulletin, 25(12), 1509-1524.

Ryan, R. M., \& Connell, J. P. (1989). Perceived locus of causality and internalization: Examining reasons for acting in two domains. Journal of Personality and Social Psychology, 57, 749-761.

Ryan, R. M., \& Deci, E. L. (2000). Self-determination theory and the facilitation of intrinsic motivation, social development, and well-being. American Psychologist, 55(1), 68-78.

Ryan, R. M., \& Deci, E. L. (2001). Self-determination theory and the facilitation of intrinsic motivation, social development, and well-being. American Psychologist, 55(1), 68-78.

Ryan, R. M., \& Deci, E. L. (2002). Overview of Self-determination theory: An organismic dialectical perspective. In E. L. Deci, \& R. M. Ryan (Eds.), Handbook of Self-determination research (pp. 3-33). Rochester, NY: The University of Rochester Press.

Ryan, R. M., \& Deci, E. L. (2003). On assimilating identities to the self: A self-determination theory perspective on internalization and integrity within cultures. In M. R. Leary, \& J. P. Tangney (Eds.), Handbook of self and identity (pp. 253-272). New York: The Guilford Press.

Ryan, R. M., \& Deci, E. L. (2004). Autonomy is no illusion: Self-determination theory and the empirical study of authenticity, awareness, and will. In J. Greenberg, S. L. Koole, \& T. Pyszczynski (Eds.), Handbook of experimental existential psychology. New York: The Guilford Press.

Ryan, R. M., \& Frederick, C. M. (1997). On energy, personality and health: Subjective vitality as a dynamic reflection of well-being. Journal of Personality, 65, 529-565.

Schmitz, P. G. (2001). Psychological aspects of immigration. In L. L. Adler, \& U. P. Gielen (Eds.), Cross-cultural topics in psychology (pp. 229-243). Westport, CT: Praeger.

Schmuck, P., Kasser, T., \& Ryan, R. M. (2000). Intrinsic and extrinsic goals: Their structure and relationship to well-being in German and U. S. college students. Social Indicators Research, 50(2), 225-241.

Schwartz, S. H. (1992). Universals in the content and structure of values: Theoretical advances and empirical tests in 20 countries. In M. Zanna (Ed.), Advances in experimental social psychology, Vol. 25 (pp. 1-16). San Diego, CA: Academic Press.

Schwartz, T. (1973). Acculturation and integration: Indian students in Winnipeg. Unpublished MA Thesis, University of Manitoba, Winnipeg.

Scott, W. A., \& Scott, R. (1989). Adaptation of immigrants: Individual differences and determinants. Oxford: Pergamon Press.

Searle, W., \& Ward, C. (1990). The prediction of psychological and sociocultural adjustment during cross-cultural transitions. International Journal of Intercultural Relations, 14, 449-464.

Selltiz, C., \& Cook, S. W. (1962). Factors influencing attitudes of foreign students toward the host country. Journal of Social Issues, 18(1), 7-23.

Selltiz, C., Crist, J. R., Havel, J., \& Cook, S. W. (1963). Attitudes and social relations of foreign students in the United States. Minneapolis: University of Minneapolis Press. 
Sheldon, K. M., Ryan, R. M., Deci, E. L., \& Kasser, T. (2004). The independent effect of goal contents and motives on well-being: It's both what you pursue and why you pursue it. Personality and Social Psychology Bulletin, 30(4), 475-486.

Srivastava, A., Locke, E. A., \& Bartol, K. M. (2001). Money and subjective well-being: It's not the money, it's the motives. Journal of Personality \& Social Psychology, 80(6), 959-971.

Tanaka, K., \& Yamauchi, H. (2000). Influence of autonomy on perceived control beliefs and self-regulated learning in Japanese undergraduate students. North American Journal of Psychology, 2, 255-272.

Tartakovsky, E., \& Schwartz, S. H. (2001). Motivation for emigration, values, well-being, and identification among young Russian Jews. International Journal of Psychology, 36(2).

Toyokawa, T., \& Toyokawa, N. (2002). Extracurricular activities and the adjustment of Asian international students: A study of Japanese students. International Journal of Intercultural Relations, 26(4), 363-379.

Vansteenkiste, M., Duriez, B., Simons, J., \& Soenens, B. (in press a). Materialistic values and well-being among business students: Further evidence for their detrimental effect. Journal of Applied Social Psychology.

Vansteenkiste, M., Lens, W., \& Deci, E. L. (in press b). Intrinsic versus extrinsic goal-contents in selfdetermination theory: Another look at the quality of academic motivation. Educational Psychologist.

Vansteenkiste, M., Simons, J., Lens, W., Sheldon, K. M., \& Deci, E. L. (2004). Motivating learning, performance, and persistence: The synergistic effects of intrinsic goal contents and autonomy-supportive context. Journal of Personality and Social Psychology, 87(2), 246-260.

Vansteenkiste, M., Zhou, M., Lens, W., \& Soenens, B. (2005). Experiences of autonomy and control among Chinese learners: Vitalizing or immobilizing? Journal of Educational Psychology, 97(3), 468-483.

Walker, J. L. (1999). Canada first: The 1999 survey of international students. Ottawa, Ont.: CBIE.

Ward, C., Bocher, S., \& Furnham, A. (2001). The psychology of culture shock (2 ed.). Hove, East Sussex: Routledge.

Ward, C., \& Kennedy, A. (1993). Psychological and sociocultural adjustment during cross-cultural transitions: A comparison of secondary students overseas and at home. International Journal of Psychology, 28, $129-147$.

Ward, C., \& Kennedy, A. (1999). The measurement of sociocultural adaptation. International Journal of Intercultural Relations, 23, 659-678.

Watson, D., Tellegen, A., \& Bartol, K. M. (1988). Development and validation of brief measures of positive and negative affect: The PANAS scales. Journal of Personality and Social Psychology, 54, 1063-1070.

Winchie, D. B., \& Carment, D. M. (1988). Intention to migrate: A psychological analysis. Journal of Applied Social Psychology, 18, 727-738.

Winter-Ebmer, R. (1994). Motivation for migration and economic success. Journal of Economic Psychology, 15, 269-284. 